\title{
Changes in operative strategy for patients enrolled in the International Registry of Acute Aortic Dissection interventional cohort program
}

\author{
Neil Parikh, BS, ${ }^{a}$ Santi Trimarchi, MD, PhD, ${ }^{\mathrm{b}}$ Thomas G. Gleason, MD, ${ }^{\mathrm{c}}$ Arnoud V. Kamman, MD, ${ }^{\mathrm{b}, \mathrm{d}}$ \\ Marco di Eusanio, MD, PhD, ${ }^{\mathrm{e}}$ Truls Myrmel, MD, PhD, ${ }^{\mathrm{f}}$ Amit Korach, MD, ${ }^{\mathrm{g}}$ Hersh Maniar, MD, \\ Takeyoshi Ota, MD, PhD, ${ }^{i}$ Ali Khoynezhad, MD, PhD ${ }^{j}$ Daniel G. Montgomery, BS, ${ }^{a}$ \\ Nimesh D. Desai, MD, PhD, ${ }^{k}$ Kim A. Eagle, MD,${ }^{a, l}$ Christoph A. Nienaber, MD, PhD, ${ }^{\mathrm{m}}$ \\ Eric M. Isselbacher, MD, ${ }^{\mathrm{n}}$ Joseph Bavaria, MD, ${ }^{\mathrm{k}}$ Thoralf M. Sundt, MD, ${ }^{\mathrm{n}}$ and Himanshu J. Patel, $\mathrm{MD}^{\mathrm{d}}$
}

\begin{abstract}
Objective: Advancements in cardiothoracic surgery prompted investigation into changes in operative management for acute type A aortic dissections over time.

Methods: One thousand seven hundred thirty-two patients undergoing surgery for type A aortic dissection were identified from the International Registry of Acute Aortic Dissection Interventional Cohort Database. Patients were divided into time tertiles (T) (T1: 1996-2003, T2: 2004-2010, and T3: 2011-2016).
\end{abstract}

Results: Frequency of valve sparing procures increased (T1: 3.9\%, T2: 18.6\%, and T3: $26.7 \%$; trend $P<.001)$. Biologic valves were increasingly utilized (T1: $35.6 \%, \mathrm{~T} 2 ; 40.6 \%$, and T3: $52.0 \%$; trend $P=.009$ ), whereas mechanical valve use decreased (T1: $57.6 \%$, T2: $58.0 \%$, and T3: $45.4 \%$; trend $P=.027$ ) for aortic valve replacement. Adjunctive cerebral perfusion use increased (T1: 67.1\%, T2: $89.5 \%$, and T3: $84.8 \%$; trend $P<.001$ ), with increase in antegrade cerebral techniques (T1: $55.9 \%$, T2: $58.8 \%$, and T3: $66.1 \%$; trend $P=.005$ ) and hypothermic circulatory arrest (T1: $80.1 \%$, T2: $85.9 \%$, and $\mathrm{T} 3: 86.8 \%$; trend $P=.030)$. Arterial perfusion through axillary cannulation increased (T1: $18.0 \%$, T2: $33.2 \%$, and T3: $55.7 \%$ ), whereas perfusion via a femoral approach diminished (T1: 76.0\%, T2: 53.3\%, and T3: 30.1\%) (both $P$ values $<.001$ ). Hemiarch replacement was utilized more frequently (T1: 27.0\%, T2: 63.3\%, and T3: $51.7 \%$; trend $P=.001$ ) and partial arch was utilized less frequently (T1: 20.7\%, T2: $12.0 \%$, and T3: $8.4 \%$; trend $P<.001$ ), whereas complete arch replacement was used similarly $(P=.131)$. In-hospital mortality significantly decreased (T1: $17.5 \%$, T2: $15.8 \%$, and T3: $12.2 \%$; trend $P=.017$ ).

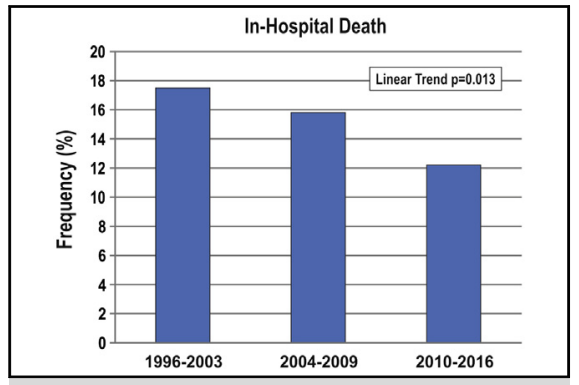

In-hospital mortality rates dropped significantly over the course of 20 years.

\section{Central Message}

Operative strategy in the management of type A aortic dissection changed and in-hospital mortality dropped significantly over a 20 -year timespan.

\section{Perspective Statement}

Over 20 years an increase was seen in the use of valvesparing procedures, bioprosthetic aortic valve substitutes, antegrade cerebral perfusion strategies, and hy pothermic circulatory arrest. With ever-evolving techniques, outcomes of surgical management of type A aortic dissection will continue to improve.

See Editorial Commentary page S80.

\footnotetext{
From the ${ }^{\text {a} M i c h i g a n ~ C a r d i o v a s c u l a r ~ O u t c o m e s ~ R e s e a r c h ~ a n d ~ R e p o r t i n g ~ P r o g r a m, ~}$ University of Michigan Health System, Ann Arbor, Mich; ${ }^{\mathrm{b}}$ Thoracic Aortic Research Center, Policlinico San Donato IRCCS, University of Milan, San Donato Milanese, Italy; ${ }^{\mathrm{c} C}$ ardiothoracic Surgery, University of Pittsburgh, Pittsburgh, Pa; Departments of ${ }^{\mathrm{d}}$ Cardiac Surgery and ${ }^{\mathrm{l}}$ Medicine, University of Michigan Frankel Cardiovascular Center, Ann Arbor, Mich; ${ }^{~}{ }^{\mathrm{C}}$ ardiac Surgery Department, University Hospital S Orsola, Bologna, Italy; ${ }^{\mathrm{f}}$ Thoracic and Cardiovascular Surgery, Tromso University Hospital, Tromso, Norway; ${ }^{\mathrm{g}}$ Cardiothoracic Surgery, Hadassah Hebrew University Medical Center, Jerusalem, Israel; hCardiovascular Surgery, Washington University, St Louis, Mo; ${ }^{i}$ Cardiac and Thoracic Surgery, University of Chicago Medical Center, Chicago, Ill; ${ }^{\mathrm{j}}$ Cardiothoracic Surgery, Cedars-Sinai Medical Center, Los Angeles, Calif; ${ }^{k}$ Cardiothoracic Surgery, University of Pennsylvania School of Medicine, Philadelphia, Pa; ${ }^{\mathrm{m}}$ Cardiology and Aortic Centre, Royal Brompton Hospital, Royal Brompton \& Harefield NHS Trust, Imperial College London, London, United Kingdom; and ${ }^{\mathrm{n}}$ Thoracic Aortic Center, Massachusetts General Hospital, Boston, Mass.

This research was supported by W.L. Gore \& Associates, Inc; Medtronic; the Varbedian Aortic Research Fund, the Hewlett Foundation; the Mardigian Foundation; UM Faculty Group Practice; Terumo; and Ann and Bob Aikens. Dr H.J.P. was generously supported by the David Hamilton Fund and the Phil Jenkins Breakthrough Fund in Cardiac Surgery at the University of Michigan Frankel Cardiovascular Center.
}

Dr H.J.P. has received consulting fees from Medtronic, Terumo, and W.L. Gore \& Associates, Inc. Dr S.T. is a consultant for Medtronic and W.L. Gore \& Associates, Inc. Dr K.A.E. has a scientific grant from W.L. Gore \& Associates, Inc, and Medtronic. Dr T.M.S. is a consultant for Thrasos Therapeutics. Dr H.M. is a consultant for Elixir Medical. Dr N.D.D. is a consultant for W.L. Gore \& Associates, Inc; Medtronic; and St Jude and has research grants from Cook Medical, Edwards Lifesciences, and St Jude Medical. Dr J.B. is a consultant for St Jude Medical and has research grants from Edwards Lifesciences; Medtronic; Vascutek; and W.L. Gore $\&$ Associates, Inc.

N.P. and S.T. contributed equally to this article.

Read at The American Association for Thoracic Surgery Aortic Symposium 2016, New York, New York, May 12-13, 2016.

Received for publication May 18, 2016; revisions received Dec 12, 2016; accepted for publication Dec 28, 2016; available ahead of print Feb 4, 2017.

Address for reprints: Himanshu J. Patel, MD, Department of Cardiac Surgery University of Michigan Hospitals, 1500 E Medical Center Dr, 5144 Frankel Cardiovascular Center/SPC 5864, Ann Arbor, MI 48109-5864 (E-mail: hjpatel@med.umich. edu).

$0022-5223 / \$ 36.00$

Copyright $(\subset 2017$ by The American Association for Thoracic Surgery http://dx.doi.org/10.1016/j.jtcvs.2016.12.029 


\section{Abbreviations and Acronyms \\ $\mathrm{CABG}=$ coronary artery bypass graft \\ HCA = hypothermic circulatory arrest \\ IVC = interventional cohort \\ IRAD = International Registry of Acute Aortic Dissection \\ $\mathrm{TAAD}=$ type $\mathrm{A}$ aortic dissection}

Conclusions: There have been significant changes in operative strategy over time in the management of type A aortic dissection, with more frequent use of valve-sparing procedures, bioprosthetic aortic valve substitutes, antegrade cerebral perfusion strategies, and hypothermic circulatory arrest. Most importantly, a significant decrease of inhospital mortality was observed during the 20-year timespan. (J Thorac Cardiovasc Surg 2017;153:S74-9)

Scanning this QR code will take you to the article title page.

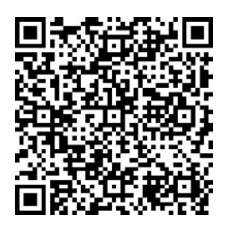

Acute aortic dissection is a lethal cardiovascular event, with an early mortality rate of up to $1 \%$ to $2 \%$ per hour if left untreated. ${ }^{1-3}$ For type A aortic dissection (TAAD), urgent surgery is indicated, with lower mortality than either medical or endovascular treatment. ${ }^{1,4,5}$ During the past several decades, cardiovascular surgery has evolved, with many advances in pharmaceuticals, devices, and procedures. ${ }^{6}$ The Interventional Cohort database (IVC) was established in 2006 as a subcohort of the International Registry of Acute Aortic Dissections (IRAD) database. Patients were included prospectively from 2006 to the present and retrospectively before 2006. The IRAD-IVC database was initiated to provide more detailed insight into surgical techniques and procedures for aortic dissection. We queried this database to investigate trends in operative management from 1996 to 2016.

\section{METHODS}

\section{Patient Selection and Data Collection}

IRAD is an observational data registry whose retrospective data collection methods have been detailed previously. ${ }^{1}$ Within IRAD, a subset of patients from participating sites that undergoes either surgical or endovascular intervention is included in the IVC Program. Details from the procedures performed at baseline are recorded on a separate, standardized form and entered into an online database managed by the IRAD coordinating center at the University of Michigan. Data are reviewed for face validity and completeness. Institutional review board approval for this study was obtained at each participating institution.

From all patients enrolled in IRAD-IVC, only TAAD patients undergoing operative repair or surgical procedure as part of a hybrid procedure were included, whereas patients undergoing type B aortic dissection and those with only endovascular or medical management were excluded. Patients were split into 3 equal groups based on time of intervention tertile (T) (T1: 1996-2003, T2: 2004-2010, and T3: 2011-2016). Arch interventions were defined. Hemiarch arch replacement $=$ only the underside of the arch replaced. Partial arch replacement $=$ only the proximal part of the arch was replaced with reimplantation of at least 1 of the brachiocephalic vessels. Complete arch replacement $=$ complete replacement of the arch of the aorta.

\section{Statistical Analysis}

Analysis of variance was performed between groups. Pairwise comparison was done to assess significance between groups, with Student $t$ test and Fischer exact test (or nonparametric tests) used where appropriate. Trend $P$ values were calculated using linear by linear association (Mantel-Haenszel test of trend). To determine independent associations, binary logistic regression analysis was used. Candidate variables with a significance $<0.20$ during univariate analysis were introduced to the model after considering clinical relevance. SPSS version 21.0 software (IBM-SPSS Inc, Armonk, NY) was used to conduct the analyses.

Furthermore, we applied a mixed model approach, containing both fixed and random effects. A mixed model is particularly useful for clusters of related statistical units. This approach was used to ensure that the effect of hospitals joining the registry in the later years did not create an unintended bias.

\section{RESULTS \\ Demographic Characteristics and In-Hospital Outcomes}

Mean age was different between the groups $(P=.011)$. There were no gender-related differences. In-hospital mortality decreased over time (T1: $17.5 \%, \mathrm{~T} 2: 15.8 \%$, and T3: $12.2 \%$; trend $P=.017$ ) (Table 1).

\section{Aortic Valve and Root Management}

When aortic valve replacement was required, use of biological valves increased over time (T1: $35.6 \%, \mathrm{~T} 2: 40.6 \%$, and T3: $52.0 \%$; trend $P=.009$ ), with a corresponding decrease in mechanical valve implantation (T1: $57.6 \%$, T2: $58.0 \%$, and T3: $45.4 \%$; trend $P=.027$ ). All results are shown in Table 2. Use of valve sparing procedures, including Yacoub remodeling or David reimplantation, increased over time (T1: $3.9 \%, \mathrm{~T} 2: 18.6 \%$, and $\mathrm{T} 3$ : $26.7 \%$; trend $P<.001$ ) (Figure 1), with no difference in use of remodeling or reimplantation surgical techniques (trend $P=.216$ ). All results are shown in Table 2.

Coronary ostium repair was used more often in the later years (T1: $4.3 \%, \mathrm{~T} 2: 11.9 \%$, and $\mathrm{T} 3: 15.0 \%$; trend $P<.001$ ), whereas the frequency of concomitant coronary artery bypass graft $(\mathrm{CABG})$ procedures was similar over time.

\section{Ascending Aorta Management}

An open distal anastomosis was used most often across all time periods. Supracoronary ascending replacement changed over time (T1: $76.4 \%, \mathrm{~T} 2: 72.5 \%$, and $\mathrm{T} 3$ : $81.7 \%$; trend $P=.004)$. The use of surgical glue declined over time (T1: $74.4 \%$, T2: $68.4 \%$, and T3: $45.0 \%$; trend $P<.001$ ), as did the use of polytetrafluoroethylene felt (T1: $89.3 \%$, T2: $85.3 \%$, and T3: $76.7 \%$; trend $P<.001$ ). Right axillary artery cannulation for inflow was used 
TABLE 1. Demographic characteristics and outcomes

\begin{tabular}{|c|c|c|c|c|c|}
\hline & Overall & Time 1 & Time 2 & Time 3 & $\begin{array}{c}\text { Trend } \\
P \text { value }\end{array}$ \\
\hline $\mathrm{N}$ & 1732 & $229(13.2)$ & $692(40.0)$ & $811(46.8)$ & - \\
\hline Mean age, y & $60.4(14.0)$ & 57.9 (13.9) & $61.2(13.8)$ & $60.4(14.1)$ & - \\
\hline Male gender & $1152(66.5)$ & $162(70.7)$ & $451(65.2)$ & $539(66.5)$ & .461 \\
\hline $\begin{array}{c}\text { In-hospital } \\
\text { death }\end{array}$ & $248(14.3)$ & $40(17.5)$ & $109(15.8)$ & $99(12.2)$ & .017 \\
\hline
\end{tabular}

more often over time (T1: $18.0 \%, \mathrm{~T} 2: 33.2 \%$, and T3: $55.7 \%$; trend $P<.001$ ), whereas femoral artery cannulation was utilized less frequently (T1: $76.0 \%$, T2: $53.3 \%$, and T3: $30.1 \%$; trend $P<.001)$.

\section{Aortic Arch Management and Cerebral Perfusion \\ Strategies}

Hemiarch replacement increased over time (T1: $27.0 \%$, T2: $63.3 \%$, and T3: $51.7 \%$; trend $P<.001$ ) (Figure 2), whereas partial arch use decreased (T1: $20.7 \%$, T2: $12.0 \%$, and T3: $8.4 \%$; trend $P<.001$ ). The percentage of complete arch replacements was similar (trend $P=.131$ ) (Figure 2), there was an increase in use of single arterial buttons (T1: $1.5 \%, \mathrm{~T} 2: 5.5 \%$, and T3: $7.3 \%$; trend $P=.003$ ), whereas branched graft use, which was the most frequently adopted, did not increase (trend $P=.600$ ). Elephant trunk techniques were used more often over time (trend $P=.002)$, whereas frozen elephant trunk use did not increase (trend $P=.914$ ). All results are shown in Table 3.

The overall use of cerebral perfusion increased over time (T1: $67.1 \%$, T2: $89.5 \%$, and T3: $84.8 \%$; trend $P<.001$ ). No hypothermic circulatory arrest (HCA) use decreased over time (T1: $21.0 \%, \mathrm{~T} 2: 14.4 \%$, and T3: $14.0 \%$; trend $P=.028$ ), use of HCA only decreased (T1: $27.8 \%$, T2: 6.7\%, and T3: $8.6 \%$; trend $P<.001)$, HCA with antegrade cerebral perfusion increased (T1: $22.0 \%, \mathrm{~T} 2: 43.4 \%$, and

TABLE 2. Aortic valve and root management

Trend

Overall Time 1 Time $2 \quad$ Time $3 \quad P$ value

\begin{tabular}{lccccc}
\hline $\begin{array}{l}\text { Commissural } \\
\text { resuspension }\end{array}$ & $531(38.0)$ & $63(30.3)$ & $267(47.9)$ & $201(31.7)$ & .067 \\
Aortic valve & $446(32.0)$ & $59(28.5)$ & $180(35.0)$ & $207(30.8)$ & .931 \\
$\quad$ replacement & & & & & \\
$\quad$ Homograft & $11(2.8)$ & $4(6.8)$ & $2(1.4)$ & $5(2.6)$ & .239 \\
$\quad$ Mechanical & $206(51.8)$ & $34(57.6)$ & $83(58.0)$ & $89(45.4)$ & .027 \\
$\quad$ Biological & $181(45.5)$ & $21(35.6)$ & $58(40.6)$ & $102(52.0)$ & .009 \\
Noncoronary sinus & $101(7.7)$ & $9(4.4)$ & $38(8.0)$ & $54(8.5)$ & .087 \\
$\quad$ replacement & & & & & \\
Valve sparing & $275(20.2)$ & $8(3.9)$ & $95(18.6)$ & $172(26.7)$ & $<.001$ \\
Remodeling & $92(47.9)$ & $1(14.3)$ & $46(60.5)$ & $45(41.3)$ & .216 \\
$\quad$ Reimplantation & $100(52.1)$ & $6(85.7)$ & $30(39.5)$ & $64(58.7)$ & .216 \\
Bentall & $337(31.1)$ & $64(30.3)$ & $121(27.6)$ & $152(35.0)$ & .099 \\
Cabrol & $14(1.3)$ & $1(0.5)$ & $7(1.6)$ & $6(1.3)$ & .506 \\
\hline
\end{tabular}

Values are presented as $\mathrm{N}(\%)$.

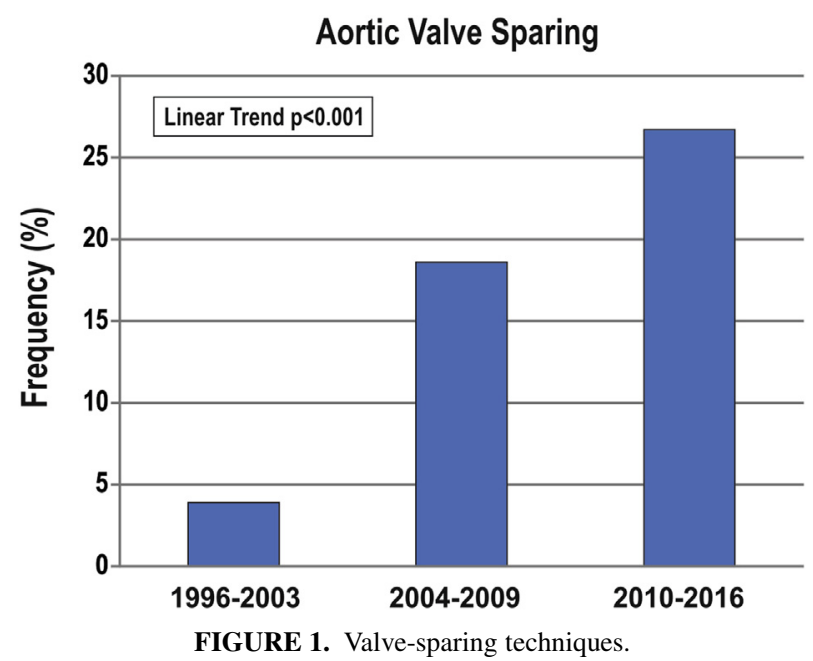

T3: $50.8 \%$; trend $P<.001$ ). HCA with retrograde perfusion did not show a clear trend over the time periods (T1: $29.3 \%$, T2: $35.5 \%$, and T3: $26.6 \%$; trend $P=.040$ ). All results are shown in Table 4.

The median temperature used for no $\mathrm{HCA}$ was $26.1^{\circ} \mathrm{C}$ (25th-75th percentiles, 25.0-28.0), for HCA only the median temperature was $18.0^{\circ} \mathrm{C}$ (25th-75th percentiles, 15.35-20.0), for HCA + antegrade perfusion the median temperature was $24.7^{\circ} \mathrm{C}$ (25th-75th percentiles, 18.827.0), and for HCA + retrograde perfusion the median temperature was $18.0^{\circ} \mathrm{C}$ (25th-75th percentiles, $\left.16.0-18.0\right)$.

\section{Multivariate Analysis}

In multivariate logistic regression analysis, adjusted for time period, we introduced the following variables: age, history of chronic renal insufficiency, renal failure, hemiarch replacement, gender, chronic obstructive pulmonary disease, pulse deficits, race, hypotension/shock/tamponade, prior cardiac surgery, use of commissural resuspension, aortic valve replacement, noncoronary sinus replacement,

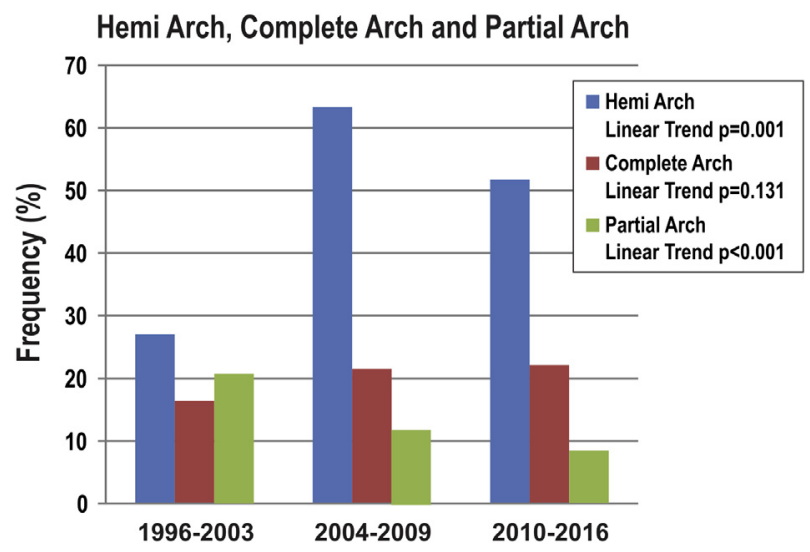

FIGURE 2. Hemiarch, complete arch, and partial arch replacement. 
TABLE 3. Aortic arch management

\begin{tabular}{|c|c|c|c|c|c|}
\hline & Overall & Time 1 & Time 2 & Time 3 & Trend $P$ value \\
\hline Hemiarch replacement & $801(52.9)$ & $55(27.0)$ & $372(63.3)$ & $374(51.7)$ & .001 \\
\hline Partial arch replacement & $162(11.6)$ & $44(20.7)$ & $62(12.0)$ & $56(8.4)$ & $<.001$ \\
\hline Complete arch replacement & $306(21.0)$ & $34(16.4)$ & $113(21.5)$ & $159(22.1)$ & .131 \\
\hline Single arterial button & $75(5.7)$ & $3(1.5)$ & $26(5.5)$ & $46(7.3)$ & .003 \\
\hline Branched graft & $145(10.8)$ & $22(10.7)$ & $57(11.8)$ & $66(10.1)$ & .600 \\
\hline Elephant trunk & $62(4.6)$ & $2(1.0)$ & $20(4.1)$ & $40(6.1)$ & .002 \\
\hline Frozen elephant trunk & $31(1.8)$ & - & $21(3.0)$ & $10(1.2)$ & .914 \\
\hline
\end{tabular}

Values are presented as $\mathrm{N}(\%)$.

valve-sparing procedure, simple ascending replacement, complete arch replacement, use of single arterial button, elephant trunk procedure, use of polytetrafluoroethylene felt, concomitant $\mathrm{CABG}$ procedure, use of $\mathrm{HCA}$, type of cerebral perfusion, and cannulation site. In the final model age, chronic renal insufficiency, renal failure, and concomitant CABG were predictors of in-hospital mortality. Use of hemiarch replacement and antegrade perfusion were negative predictors of mortality (Table 5).

\section{Mixed Model Approach}

From our mixed model approach, correcting for the site of the operative procedure, we identified renal failure, age $>70$ years, and concomitant CABG procedure as predictors of mortality, whereas a hemiarch procedure and antegrade cerebral perfusion were negative predictors of mortality (Table 6). More importantly, mortality was less likely for patients undergoing operation in later years (odds ratio, $0.938 ; P=.03$ ). In other words, the reduction of mortality over time we observed in our main analysis was not related to an unintentional bias created by the inclusion of hospitals that joined the database in the later years.

\section{DISCUSSION}

Multiple advances in operative management in cardiac surgery have occurred since the initiation of IRAD in 1996. As the largest registry of acute aortic dissections, IRAD was the ideal database to evaluate trends of such advances as well as identify any potential changes in mortality after aortic repair.

The percentage of valve-sparing operations increased over time. Preservation of the native valve has several advantages, including freedom from anticoagulation therapy, and increasing evidence of a lower rate of valverelated compications. ${ }^{7-10}$ However, extended operative times are required by valve-sparing procedures, in particular in those patients who also require complete arch repair, carry the risk of longer cardiopulmonary bypass time, which may explain the lower frequency of valve-sparing procedures in earlier time periods. Improvements in circulatory management approaches may have contributed to the observed rise in valve-sparing procedures, although the true reasons remain unclear. The frequency of valvesparing procedures increased, but overall use was similar between the Yacoub remodeling and David reimplantation approaches. There have been many shifts in preference between these 2 procedures, and selection criteria are poorly defined. In addition, many surgeons have developed their own preferences over time. ${ }^{11}$ When aortic valve replacement was required, we observed a trend in increased use of xenograft biological prostheses with a concomitant decrease in mechanical valve substitutes. This phenomenon may be explained by the improved longevity of current era biological valves as well as improved reported results of reoperative surgery for failed prosthetic aortic valves. ${ }^{12}$

It is interesting to note that the use of surgical glue has declined. Although no survey of participants was obtained to determine the reason for its decrease, a potential explanation could relate to its perceived toxicity. Of the numerous surgical glues, BioGlue (albumin and glutaraldehyde [CryoLife Inc, Kennesaw, Ga]) is most commonly used. However there has been concern over glutaraldehyde toxicity, as well as the risk of adhesive embolization. ${ }^{13,14}$ Moreover, there have been several articles suggesting that BioGlue is less

TABLE 4. Cerebral perfusion management

\begin{tabular}{|c|c|c|c|c|c|}
\hline & Overall & Time 1 & Time 2 & Time 3 & Trend $P$ value \\
\hline Cerebral perfusion & $1256(84.2)$ & $141(67.1)$ & $528(89.5)$ & $587(84.8)$ & $<.001$ \\
\hline No HCA & $213(15.2)$ & $43(21.0)$ & $79(14.4)$ & $91(14.0)$ & .028 \\
\hline HCA only & $150(10.7)$ & $57(27.8)$ & $37(6.7)$ & $56(8.6)$ & $<.001$ \\
\hline $\mathrm{HCA}+$ antegrade perfusion & $613(43.7)$ & $45(22.0)$ & $238(43.4)$ & $330(50.8)$ & $<.001$ \\
\hline $\mathrm{HCA}+$ retrograde perfusion & $428(30.5)$ & $60(29.3)$ & $195(35.5)$ & $173(26.6)$ & .040 \\
\hline Duration in minutes, median (25th-75th quartiles) & $55(40-65)$ & $58.5(39.25-68)$ & $52(40-63)$ & $56(40-65.75)$ & - \\
\hline
\end{tabular}

Values are presented as $\mathrm{N}(\%)$ unless otherwise noted. $H C A$, Hypothermic circulatory arrest. 
TABLE 5. Multivariate analysis of all patients from the study cohort*

\begin{tabular}{|c|c|c|c|c|}
\hline Variable & Odds ratio & $\begin{array}{c}\text { Lower } 95 \% \\
\text { Confidence } \\
\text { interval }\end{array}$ & $\begin{array}{c}\text { Upper } 95 \% \\
\text { Confidence } \\
\text { interval }\end{array}$ & $P$ value \\
\hline Age & 1.031 & 1.013 & 1.050 & .001 \\
\hline $\begin{array}{l}\text { History of chronic renal } \\
\text { insufficiency }\end{array}$ & 2.264 & 1.046 & 4.897 & .038 \\
\hline Renal failure & 3.247 & 2.024 & 5.209 & $<.001$ \\
\hline Hemiarch replacement & 0.518 & 0.323 & 0.831 & .006 \\
\hline $\begin{array}{l}\text { Concomitant CABG } \\
\text { procedure }\end{array}$ & 3.435 & 1.858 & 6.352 & $<.001$ \\
\hline $\begin{array}{l}\text { Antegrade cerebral } \\
\text { perfusion }\end{array}$ & 0.435 & 0.241 & 0.785 & .006 \\
\hline
\end{tabular}

compliant than other sealants, such as synthetic surgical glue. ${ }^{15,16}$ Such controversy may have contributed to the decreasing use of surgical glue identified in this study.

Extended arch repair, which included partial and complete arch repair, was used in more than one-third of patients. Recent developments support increased safety of these operations without increasing operative mortality and morbidity compared with hemiarch replacement. ${ }^{17}$ However, complete arch replacement showed no significant change over time within the IVC database, whereas partial arch repair was utilized less in more recent years. HCA is used on the basic premise that hypothermia depresses cerebral metabolism enough to allow a safe period of total circulatory arrest, thereby preventing functional or organ injuries after surgery. ${ }^{18} \mathrm{HCA}$ is also used when constructing more limited arch replacement (eg, open distal anastomosis or hemiarch) to allow for a more complete resection of the aorta without need to address branch vessel regions. However, a key concern with its use in aortic dissection repair is duration. As the duration of HCA increases, morbidity and mortality markedly increase. ${ }^{19-21}$ The 2 approaches of retrograde cerebral perfusion and antegrade cerebral perfusion have been largely used $(>80 \%)$ to reduce the incidence of neurologic injury with protracted HCA times. Retrograde cerebral perfusion delivers oxygenated blood from the cardiopulmonary bypass circuit into the

TABLE 6. Mixed model outcomes

\begin{tabular}{lccr}
\hline \multicolumn{1}{c}{ Variable } & Beta coefficient & Odds ratio & $\boldsymbol{P}$ value \\
\hline IRAD admission year & -0.06372 & 0.938 & .03 \\
Age $>70$ y & 0.6543 & 1.924 & .004 \\
Renal failure & 1.4294 & 4.176 & $<.001$ \\
Simple ascending & -0.305 & 0.737 & .229 \\
$\quad$ replacement & & & \\
Hemiarch replacement & -0.6612 & 0.516 & .006 \\
Concomitant CABG & 1.1634 & 3.200 & $<.001$ \\
Antegrade cerebral perfusion & -0.8366 & 0.433 & .008 \\
\hline
\end{tabular}

IRAD, International Registry of Acute Aortic Dissection; $C A B G$, coronary artery bypass graft. superior vena cava to provide cerebral perfusion in a retrograde fashion, whereas antegrade cerebral perfusion directs blood to the arch vessels to perfuse the brain in an antegrade manner. Although once widely used, the ability of retrograde cerebral perfusion to oxygenate the brain has been questioned, and there has been little evidence to support a significant level of neuroprotection. ${ }^{22,23}$ Within the IVC database, when cerebral perfusion was used, the increased proportion of antegrade cerebral perfusion and concomitant decrease in retrograde cerebral perfusion align with the current understanding of the effectiveness and neuroprotection of antegrade cerebral perfusion and retrograde cerebral perfusion. The increased use of antegrade cerebral perfusion observed in the IVC database might be performed in conjunction with moderate temperatures in an effort to avoid complications of prolonged deep HCA. ${ }^{23}$

Most importantly, a significant reduction of in-hospital mortality was observed over 20 years (from $\sim 18 \%$ to $\sim 12 \%$ ). The results improved despite increasing the complexity of aortic repair. A possible hypothesis is that the observed trends of improved perfusion strategies and organ protection, as well as increasing experience, likely contributed to a reduction in in-hospital mortality. Similar findings were identified in an analysis of the Nationwide Inpatient Sample by Knipp and colleagues. ${ }^{24}$ The limitations of their database revolve around the lack of clinical variables, which are robustly populated in IRAD-IVC. Future studies will focus on potential sources of these improved outcomes.

As with all observational studies, there are some limitations to this study. Our patient cohort was treated in specialized aortic centers, and may therefore differ from the general population. Therefore, extrapolation of our results to other hospitals may not be valid. Furthermore, diagnostic image acquisition at IRAD centers and referral centers is not protocol-driven, and various types of data acquisition techniques may have been used. Nonetheless, the criteria within IRAD centers regarding diagnostics are strict and experienced physicians evaluate all imaging data.

\section{CONCLUSIONS}

There have been significant changes in operative strategy over time in the management of TAAD, with more frequent use of valve-sparing procedures, bioprosthetic aortic valve substitutes, antegrade cerebral perfusion strategies, and HCA. More important, a significant decrease of inhospital mortality was observed during the 20-year timespan.

\section{Conflict of Interest Statement}

Dr Patel has received consulting fees from Medtronic, Terumo, and W. L. Gore. This study was partially funded by W. L. Gore. Dr Trimarchi is a consultant for Medtronic and W. 
L. Gore. Dr Eagle has a scientific grant from W. L. Gore and Medtronic. Dr Sundt is a consultant for Thrasos Therapeutics. Dr Maniar is a consultant for Elixir Medical. Dr Desai is a consultant for W. L. Gore, Medtronic, and St. Jude, and has research grants from Cook Medical, Edwards Lifescience, and St. Jude Medical. Dr Bavaria is a consultant for St. Jude Medical and has research grants from Edwards Lifescience, Medtronic, Vascutek, and W. L. Gore. All other authors have nothing to disclose with regard to commercial support.

\section{References}

1. Hagan PG, Nienaber CA, Isselbacher EM, Bruckman D, Karavite DJ, Russman PL, et al. The International Registry of Acute Aortic Dissection (IRAD): new insights into an old disease. JAMA. 2000;283:897-903.

2. Meszaros I, Morocz J, Szlavi J, Schmidt J, Tornoci L, Nagy L, et al. Epidemiology and clinicopathology of aortic dissection. Chest. 2000;117:1271-8.

3. Hirst AE Jr, Johns VJ Jr, Kime SW Jr. Dissecting aneurysm of the aorta: a review of 505 cases. Medicine (Baltimore). 1958;37:217-79.

4. Mehta RH, O'Gara PT, Bossone E, Nienaber CA, Myrmel T, Cooper JV, et al. Acute type A aortic dissection in the elderly: clinical characteristics, management, and outcomes in the current era. J Am Coll Cardiol. 2002; 40:685-92.

5. Nienaber CA, Eagle KA. Aortic dissection: new frontiers in diagnosis and management: part I: from etiology to diagnostic strategies. Circulation. 2003;108: 628-35.

6. Iribarne A, Russo MJ, Moskowitz AJ, Ascheim DD, Brown LD, Gelijns AC. Assessing technological change in cardiothoracic surgery. Semin Thorac Cardiovasc Surg. 2009;21:28-34.

7. Stassano P, Di Tommaso L, Monaco M, Iorio F, Pepino P, Spampinato N, et al. Aortic valve replacement: a prospective randomized evaluation of mechanical versus biological valves in patients ages 55 to 70 years. J Am Coll Cardiol. 2009;54:1862-8.

8. Lilly L. Valvular heart disease. 5th ed. New York: Wolters Kluwer/Lippincott, Williams \& Wilkins; 2011.

9. Giebels C, Aicher D, Kunihara T, Rodionycheva S, Schmied W, Schafers HJ. Causes and management of aortic valve regurgitation after aortic valve reimplantation. J Thorac Cardiovasc Surg. 2013;145:774-80.

10. Lausberg H, Schäfers H. Valve sparing aortic replacement-root remodeling. Multimedia Manual Cardiothorac Surg. January 1, 2006; doi.org/10.1510/ mmcts.2006.001982.
11. Rahnavardi M, Yan TD, Bannon PG, Wilson MK. Aortic valve-sparing operations in aortic root aneurysms: remodeling or reimplantation? Interact Cardiovasc Thorac Surg. 2011;13:189-97.

12. Moorjani N, Sunil K, Wechsler A. Aortic valve replacement. In: Cardiac Surgery: Recent Advances and Techniques. Boca Raton, FL: CRC Press; 2013.

13. LeMaire SA, Carter SA, Won T, Wang X, Conklin LD, Coselli JS. The threat of adhesive embolization: BioGlue leaks through needle holes in aortic tissue and prosthetic grafts. Ann Thorac Surg. 2005;80:106-10; discussion 10-1.

14. Mehdizadeh M, Yang J. Design strategies and applications of tissue bioadhesives Macromol Biosci. 2013;13:271-88.

15. Azadani AN, Matthews PB, Ge L, Shen Y, Jhun CS, Guy TS, et al. Mechanica properties of surgical glues used in aortic root replacement. Ann Thorac Surg. 2009;87:1154-60.

16. Lemaire SA, Ochoa LN, Conklin LD, Schmittling ZC, Undar A, Clubb FJ Jr, et al. Nerve and conduction tissue injury caused by contact with BioGlue. J Surg Res. 2007; 143:286-93.

17. Li B, Ma WG, Liu YM, Sun LZ. Is extended arch replacement justified for acute type A aortic dissection? Interact Cardiovasc Thorac Surg. 2015;20:120-6.

18. Di Bartolomeo R, Pilato E, Pacini D, Savini C, Di Eusanio M. Cerebral protection during surgery of the aortic arch. Multimed Man Cardiothorac Surg. 2011; 2011(221):mmcts.2010 004457.

19. Khaladj N, Shrestha M, Meck S, Peterss S, Kamiya H, Kallenbach K, et al. Hypothermic circulatory arrest with selective antegrade cerebral perfusion in ascending aortic and aortic arch surgery: a risk factor analysis for adverse outcome in 501 patients. J Thorac Cardiovasc Surg. 2008;135:908-14.

20. Strauch JT, Spielvogel D, Lauten A, Galla JD, Lansman SL, McMurtry K, et al Technical advances in total aortic arch replacement. Ann Thorac Surg. 2004;77: 581-9; discussion 589-90.

21. LeMaire SA, Gopaldas RR, Coselli JS. Thoracic aneurysms and aortic dissection. In: Brunicardi FC, Andersen DK, Billiar TR, Dunn DL, Hunter JG, Matthews JB, et al., eds. Schwartz's principles of surgery. 10th ed. New York: McGraw-Hill Education; 2014.

22. Ehrlich MP, Hagl C, McCullough JN, Zhang N, Shiang H, Bodian C, et al. Retrograde cerebral perfusion provides negligible flow through brain capillaries in the pig. J Thorac Cardiovasc Surg. 2001;122:331-8.

23. Luehr M, Bachet J, Mohr FW, Etz CD. Modern temperature management in aortic arch surgery: the dilemma of moderate hypothermia. Eur J Cardiothorac Surg. 2014;45:27-39.

24. Knipp BS, Deeb GM, Prager RL, Williams CY, Upchurch GR Jr, Patel HJ. A contemporary analysis of outcomes for operative repair of type A aortic dissection in the United States. Surgery. 2007;142:524-8; discussion 528.e1.

Key Words: aortic dissection, surgical management, trends, survival, operative strategy 